\title{
heterogeneidades de la composición química en el hormigón
}

\author{
J. CALLEJA (') F. TRIVIÑo (2) Y B. BACLE (3)
}

\begin{abstract}
Se aborda, por vez primera, el problema de la heterogeneidad del hormigón desde el punto de vista quimico, en relación con el enjuiciamiento del material desde diversos puntos de vista tecnológicos de calidad y comportamiento. Se ponen de relieve las causas $y$ los mecanismos varios que pueden provocar en el hormigón heterogeneidades de naturaleza química, y se destaca el hecho de que la heterogeneidad se da preferentemente en los hormigones deficientes en algún aspecto, y tanto más cuanto más numerosas $y$ mayores sean las deficiencias. Se hacen destacar las condiciones en que debe basarse un estudio químico en el que se pueda asentar una valoración y calificación del material, y se subrayan las consecuencias que puede tener el realizar dicho estudio a la ligera, particularmente en lo que respecta a la utilización de muestras inadecuadas.
\end{abstract}

\section{INTRODUCCIÓN: LA HETEROGENEIDAD DEL HORMIGÓN}

El hormigón, como material pétreo artificial, es un conglomerado constituido por áridos pétreos naturales -en las dosis convenientes y con las granulometrías adecuadas-, un conglomerante -generalmente un cemento artificial- y agua. El agua y el conglomerante forman una pasta con una consistencia apropiada, que recubre los granos de árido fino - arenay rellena los huecos entre ellos. A su vez, el conjunto de pasta y arena constituye el mortero que rellena los huecos entre los áridos más gruesos -gravilla y grava-. El fraguado y endurecimiento de la pasta da trabazón al conjunto, "cementando" entre sí los diversos áridos, con lo que da lugar al conglomerado pétreo.

El comportamiento del hormigón desde los tres puntos de vista principales que sirven para enjuiciarlo, resistencias mecánicas, estabilidad de volumen y durabilidad -o resistencia química frente a diversos medios agresivos-, depende de una serie de factores, entre los que destacan la compacidad y la homogeneidad. La primera afecta principalmente a la resistencia química del hormigón, así como a su resistencia frente a las heladas, aunque también a la resistencia mecánica, mientras que la segunda atañe más a ésta y a la estabilidad de volumen, sin dejar de influir en la durabilidad.

(1) Doctor en Ciencias Químicas; Investigador Jefe del Departamento de Química del Instituto «Eduar-

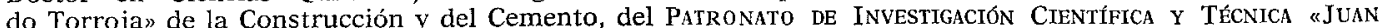

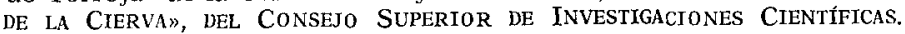

(2) Licenciado en Ciencias Químicas; de la Sección de Espectrometría del citado Departamento

(3) Perito Industrial Químico; de la Sección de Fisicoquímica del repetido Departamento. 
No es fácil definir la homogeneidad de un material que como el hormigón es esencialmente heterogéneo por naturaleza, sobre todo si se considera desde un punto de vista microscópico. No obstante, puede admitirse que macroscópicamente es homogéneo un hormigón cuando lo es la pasta cementante y el mortero de que está formado, y cuando el reparto de los áridos gruesos es uniforme en la masa de aquéllos. Es decir, cuando la distribución de todos sus componentes se produce al azar, sin orientaciones ni acumulaciones locales de los mismos, esto es, cuando, considerada desde este punto de vista una parte cualquiera de la masa del conglomerado, es comparable a cualquier otra porción del mismo de tamaño análogo.

Varias son las causas por las que un hormigón tiende a no ser homogéneo, incluso macroscópicamente. Entre ellas, una es la natural tendencia a la segregación de los materiales más gruesos; otra, el fenómeno lógico de la sedimentación; otra, el fenómeno del exudado o reflujo de la lechada de cemento hacia la superficie o, en general, hacia las partes exteriores de la masa. Esto último se da particularmente en hormigones muy fluidos. En todo ello interviene la naturaleza de los materiales $\mathrm{y}$, sobre todo, la granulometría, la dosificación y la relación agua/cemento -o su inversa, la concentración, o relación cemento/agua-.

Aparte de estas causas, contribuyen o pueden contribuir también a la heterogeneidad del hormigón, en uno u otro aspecto, y en mayor o menor medida, ciertas operaciones, prácticas y elementos necesarios en la tecnología de este material, como son el vertido, el apisonado, el vibrado y los encofrados. Estos últimos, según sea su forma, dimensiones, colocación y material de que estén hechos, producen un cierto «efecto pared», permiten con mayor o menor facilidad una cierta pérdida de lechada por escurrimiento, o absorben y enjugan una determinada proporción del agua de la masa.

Por otra parte, los fenómenos de difusión, que tenderían a neutralizar en parte alguna de estas causas de heterogeneidad, son lentos en general, y también lo son en el hormigón, máxime cuando, como en el caso de este material, se trata de un sistema que, a partir de un instante dado - fraguado-, se rigidiza por momentos, impidiendo o dificultando la difusión.

Por todas estas razones no es aventurado considerar al hormigón como un material razonablemente heterogéneo, aun macroscópicamente.

\subsection{Heterogeneidad de masa a superficie}

En Fisicoquímica es clásico considerar que toda superficie límite de separación -o de contacto- entre fases constituye una heterogeneidad en un sistema, hasta el punto de que se definen como sistemas heterogéneos aquellos que están constituidos por diferentes fases y constan, por tanto, de las correspondientes interfases o superficies límite entre ellas. Individualmente consideradas, las fases son homogéneas.

Si se da a este concepto la debida extensión, se viene a concluir, en buena concordancia con lo expuesto en el punto I, que son precisamente aquellas zonas del hormigón, en contacto o más próximas con respecto al medio ambiente, al fondo de los moldes o a las paredes de los encofrados, las más susceptibles de presentar diferencias con las zonas interiores del mismo hormigón. Las zonas próximas al medio ambiente - en general, las caras vistas superiores del hormigón, aun cuando esté enmoldado-, por los fenómenos de exudación («bleeding») y por efectos atmosféricos - de carbonatación principalmente, descontando posibles lavados-; las zonas del fondo, por la sedimentación y por las eventuales pérdidas de lechada («leakage»); las zonas próximas a los encofrados, por el efecto pared y por la eventual 
absorción; las zonas de las esquinas por lo mismo $\mathrm{y}$, en algunas ocasiones, también por pérdida de lechada.

\subsection{Naturaleza de la heterogeneidad}

La heterogeneidad debida a la no uniforme distribución de los áridos gruesos -e incluso de los áridos finos- es una heterogeneidad que puede calificarse de física. En cambio, la heterogeneidad atribuible a un distinto reparto de pasta es ya calificable de quimica. Lo primero se justifica por una naturaleza convencionalmente inerte -en general- de los áridos; lo segundo, por una naturaleza ciertamente activa - desde un punto de vista químico- del conglomerante. Como el desigual reparto de los áridos implica necesariamente un reparto análogamente desigual de la pasta, la heterogeneidad del hormigón, a fin de cuentas, tiene siempre naturaleza y repercusiones químicas.

La pasta en sí, a su vez, tampoco es siempre homogénea; en todo caso, hay circunstancias en que existen razones para que no lo sea. Como en otro lugar se ha expuesto, esta falta de homogeneidad se manifiesta en diferencias de composición química, las cuales repercuten en las propiedades y en el comportamiento, no sólo químico, sino también físico y mecánico de dichas pastas- particularmente en cuanto a estabilidad de volumen se refiere (1).

\subsection{Heterogeneidad química de las pastas (1).}

En ciertas condiciones, las pastas puras de cemento fraguadas presentan notables diferencias, tanto de composición como de constitución química entre sus partes externas y el interior de su masa, lo cual ha podido ser revelado por el simple análisis químico y por aplicación de métodos roentgenográficos. Tales diferencias se resumen en un mayor contenido de pérdidas al fuego, de dióxido de carbono fijado, de $\mathrm{SO}_{3}$ y de álcalis, y en un contenido menor de agua de hidratación - combinada-, así como en una menor relación $\mathrm{SO}_{3} /$ álcalis, en las partes externas con relación a las internas de la masa de pasta. Esto, por lo que respecta a la composición química; por lo que atañe a la constitución, los rayos $\mathrm{X}$ han revelado, en justa correspondencia, una mayor presencia de carbonato cálcico y de ettringita, y una presencia menor de portlandita y de sulfoaluminato cálcico monosulfato hidratado, en las zonas exteriores con respecto a las interiores.

La explicación de estos hechos reside: a) en fenómenos de exudación que hacen refluir a la superficie o parte externa de las pastas de cemento una lechada más fluida, rica en partículas finas de cemento y de yeso, y más rica también en álcalis y sulfatos solubles -y eventualmente en cloruros- que el resto; $b$ ) en fenómenos de evaporación y carbonatación superficiales, subsiguientes a la exudación, con una penetración limitada.

Esto se da con mayor facilidad en pastas de consistencia blanda, muy trabajadas, y cuando el cemento tiene defectos de finura o granulometría.

La consecuencia de todo ello es un comportamiento diferencial de las partes externas e internas de la pasta, en cuanto se refiere a fraguado y retracción principalmente, que se manifiesta a veces en fisuraciones y agrietamientos superficiales, con los consiguientes efectos de orden secundario en cada caso. 


\subsection{Heterogeneidad química de los hormigones}

Las posibles diferencias de reparto de pasta en un hormigón, tal como se señala en el punto 1.2, y la también posible falta de homogeneidad de la propia pasta, según se acaba de exponer en 1.3, pueden dar lugar, concurrien do a un mismo fin, a una heterogeneidad del hormigón, de naturaleza doblemente química, que responda sustancialmente a los principios expuestos en los puntos 1.1 y 1.3.

Por razones análogas a las aducidas al tratar de la heterogeneidad química de las pastas (1), así como por lo expuesto en el punto I., la heterogeneidad química de los hormigones lógicamente se dará más fácil y acusadamente en aquellos hormigones con alguna deficiencia de dosificación, de granulometría de áridos, de relación agua/cemento, de amasado o de puesta en obra - vertido, picado, apisonado, vibrado, inyectado, etc.-; en hormigones, en suma, deficientes por su cálculo, por sus materiales o por su ejecución. Y más todavía si las deficiencias se deben, no a una, sino a varias causas.

En lo que sigue se trata de poner de manifiesto heterogeneidades de tipo químico en materiales ciertamente mediocres y pobres, extraídos de diversas obras, en parangón con materiales cuidados, confeccionados en laboratorio y con todo esmero. Igualmente se señalan las consecuencias y alcance que dichas heterogeneidades puedan tener en diversos órdenes.

\section{PARTE EXPERIMENTAL}

\subsection{Materiales}

Para la realización de la parte experimental de este trabajo se han utilizado diversas probetas de hormigones distintos, cuatro de ellos tomados de obras estructurales en curso de realización, y otro tomado de una viga experimental.

Los cuatro primeros fueron hormigones defectuosos, de baja dosificación en material conglomerante activo, poco densos, poco compactos, poco resistentes y hasta deleznables a veces, cuyo árido grueso era calizo y cuyo árido fino estaba constituido por caliza de machaqueo $\mathrm{y}$, en ocasiones, arena de playa; hormigones, en suma, cuya heterogeneidad física se podía apreciar a simple vista. Se denominarán hormigones $1,2,3$ y 4, respectivamente, y pueden apreciarse en la fotografía de la figura 1.

El quinto hormigón fue un buen hormigón de laboratorio, calculado para una viga experimental, denso, resistente, bien dosificado y compactado, confeccionado con un conglomerante de garantía, cuyo árido grueso era canto rodado limpio y cuyo árido fino era arena de río; un hormigón que podría considerarse como física y macroscópicamente homogéneo. Se denominará hormigón 5 y puede apreciarse en la fotografía de la figura 2 .

Las probetas se extrajeron en todos los casos con broca perforadora de corona de diamante, en forma de tochos cilíndricos de unos $10 \mathrm{~cm}$ de diámetro y altura aproximada de unos $20 \mathrm{~cm}$; unas procedían de pilares y otras de forjados. De estas probetas, utilizadas para el ensayo de rotura a compresión, se aprovecharon los restos, considerando, según los casos, tres zonas en cada una (fig. 5): la zona $A$, más superficial o externa; la zona $A^{\prime}$, intermedia, pero con carácter más superficial que interno, y la zona $B$, interna. Nunca se dieron en una misma probeta las tres zonas, pues, disponiendo siempre de la $A$, unas veces faltó la $A^{\prime}$ y otras la $B$. 


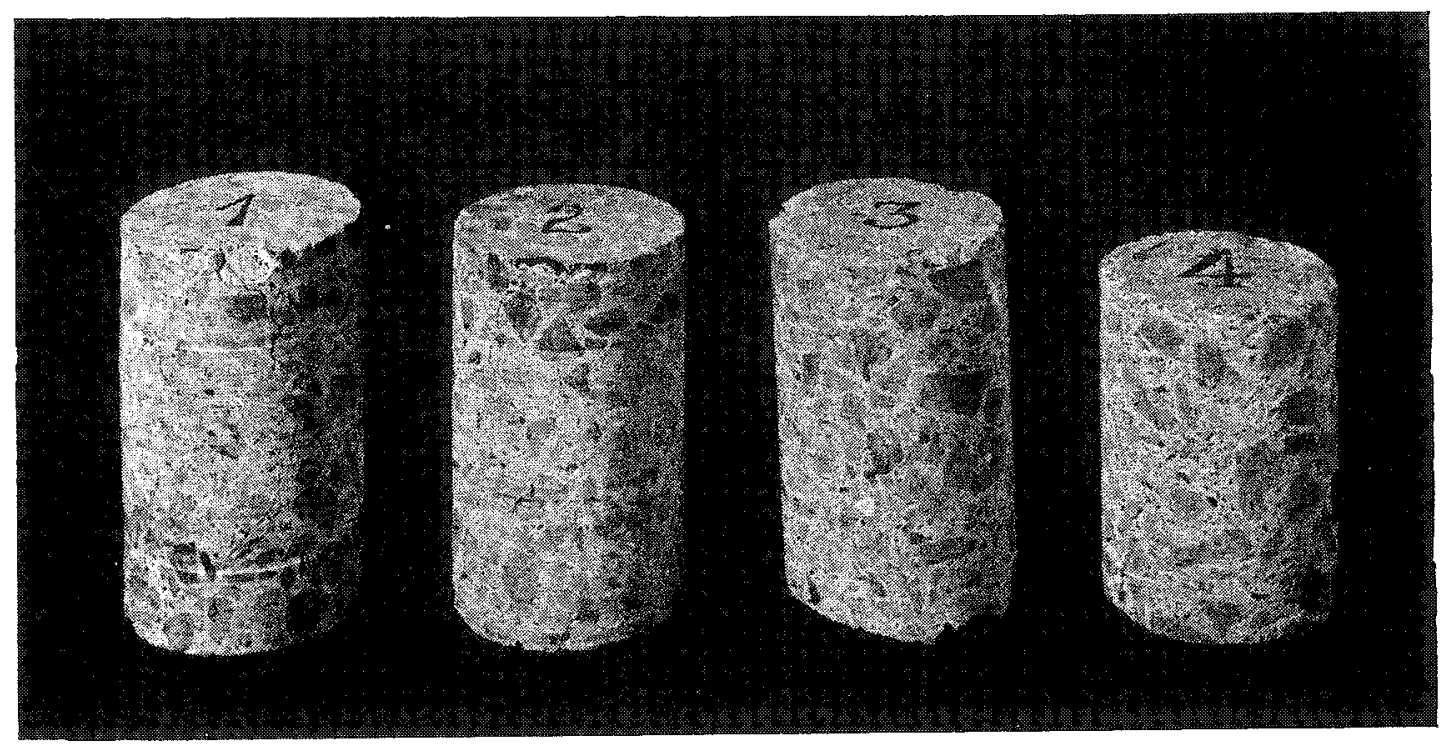

Fig. 1.
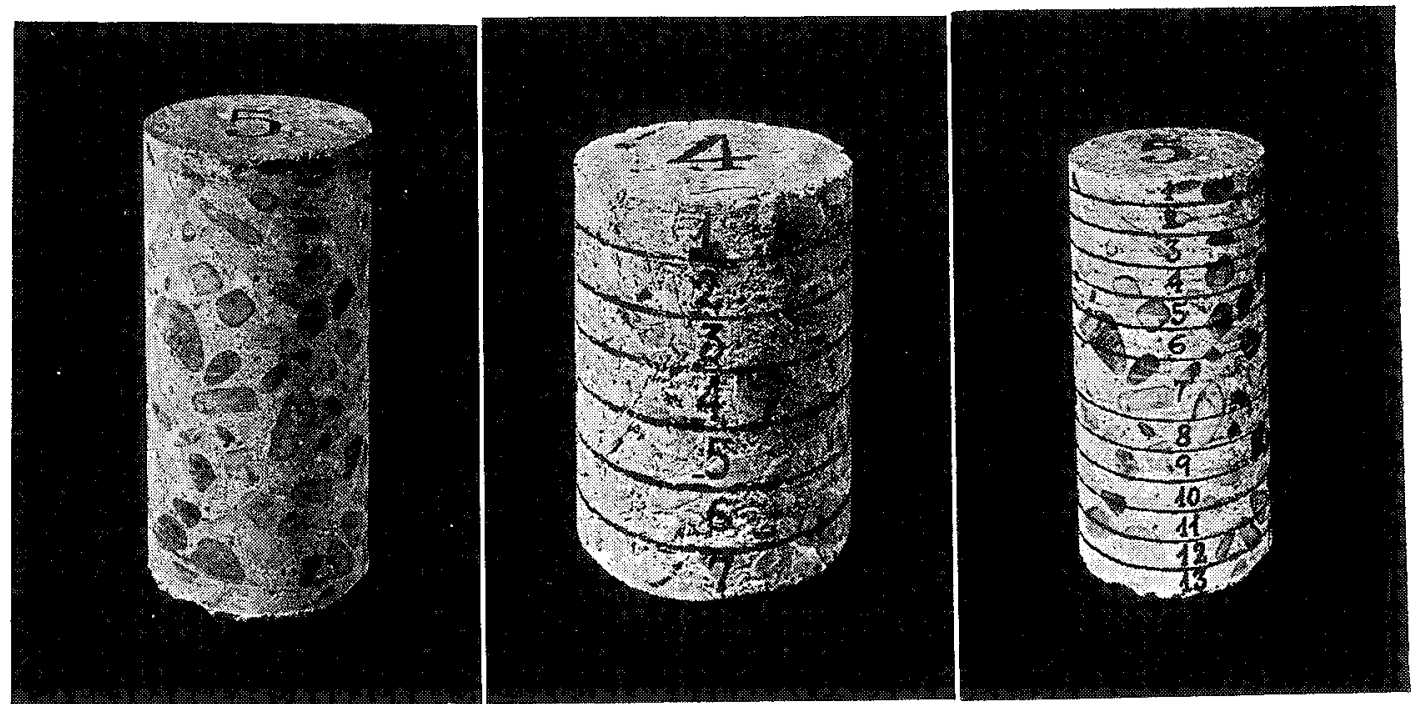

Figs. 2, 3 y 4

El espesor absoluto y relativo de estas zonas varió en las distintas probetas de un mismo hormigón y de hormigones diferentes, pero en todo caso se determinó el peso utilizado de cada zona. Es preciso tener en cuenta, como se verá después, que el agua empleada en la perforación actuó de preferencia, afectándola más, sobre la cara externa o superficial de la zona $A$, y que el efecto del consiguiente "lavado», a fines analíticos, es tanto más sensible cuanto menor es el espesor o peso de la zona $A$ considerada.

Las probetas de los hormigones 4 y 5 se cortaron en lajas, en la forma indicada en los es- 


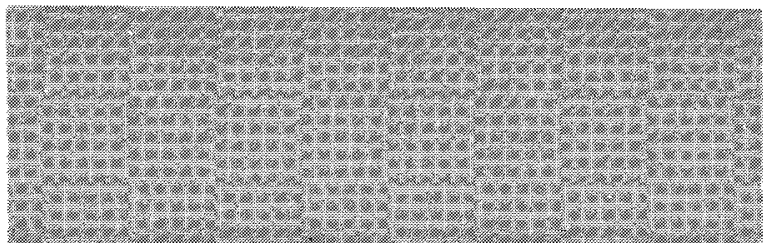

quemas de las figuras 3 y 4 ; la del hormigón 4, en 7 lajas tla 1 y la 7 con un espesor de 0,5 a $1 \mathrm{~cm}$ y las restantes de 1,5, a $2 \mathrm{~cm}$ ), y la del hormigón 5 , en 13 lajas de un espesor de 1,5 a 2 $\mathrm{cm}$ (la central 7 doble). Como en el caso de las zonas $A, A^{\prime}$ y. B, se determinó el peso de cada laja.

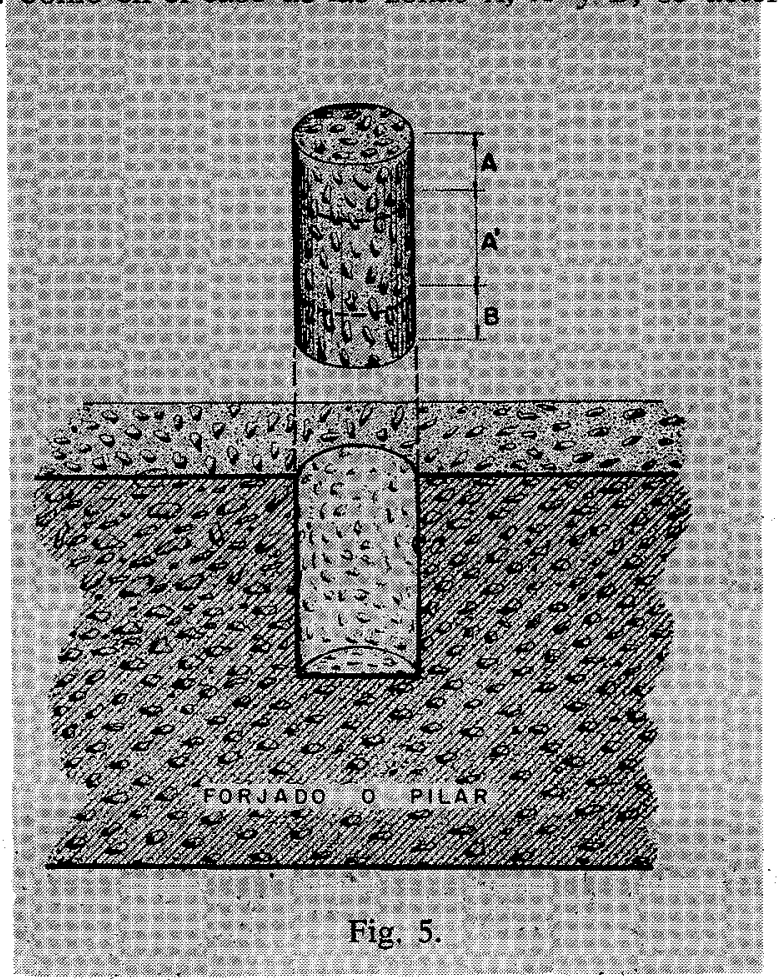

\subsection{Métodos}

Con las muestras de zonas y las lajas se procedió a su preparación para someterlas a las distintas operaciones analíticas.

2.2.1 PREPARACróN DE MUESTRAS. - Consis tió en una trituración en seco, a fondo, hasta reducir cada muestra a una finura tal que su totalidad pasase por un tamiz de 4.900 mallas $/ \mathrm{cm}^{2}-88$ micras en luz de malla-. Al propio tiempo que se procedía a la trituración en un molino de bolas vibratorio, se conseguía también la perfecta homogeneización de cada muestra.

2.2.2 TÉCNICAS, ÁnALÍticas.-En cada muestra se determinó por vía química el contenido de cloruros expresados como cloro-ión, por el método de clarke (2), y el contenido de sulfatos, expresado como $\mathrm{SO}_{3}$, por el método gravimétrico clásico del sulfato bárico.

Por fotometría de llama se determinó el contenido de álcalis (óxido sódico y óxido potásico por separado), utilizando para ello un equipo Beckman DU (3).

Por espectrometría de rayos X (fluorescencia) se determinó adicionalmente, en el caso del hormigón 4, el contenido de azufre, expresándolo como $\mathrm{SO}_{3}$, y habiendo utilizado para ello un equipo Philips (4).

\subsection{Resultados}

2.3.1. Presentactón.-En tres series de cuadros, correspondientes cada uno de ellos a los hormigones 1, 2 y 3, respectivamente, se dispusieron los valores analíticos hallados, así como ciertas relaciones entre algunos de ellos con indicación del número de muestra y de la 
zona $A, A^{\prime}$ o $B$ considerada en cada caso. Estos valores analíticos y dichas relaciones fueron: contenido de $\mathrm{Cl}-\%$; contenido de $\mathrm{SO}_{3} \%$; contenido de $\mathrm{Na}_{2} \mathrm{O} \%$; contenido de $\mathrm{K}_{2} \mathrm{O} \%$; contenido suma de $\mathrm{Na}_{2} \mathrm{O}+\mathrm{K}_{2} \mathrm{O} \%$; relación $\mathrm{Cl}-\% / \mathrm{Na}_{2} \mathrm{O} \%+\mathrm{K}_{2} \mathrm{O} \%$ y relación $\mathrm{SO}_{3} \% / \mathrm{NA}_{2} \mathrm{O} \%+\mathrm{K}_{2} \mathrm{O}$ por 100 .

Las muestras fueron 12 probetas del hormigón 1, 10 del hormigón 2 y 12 del hormigón 3, con sus correspondientes zonas $A, A^{\prime} \circ B$. En los cuadros se hicieron figurar también los pesos del material correspondiente a cada una de las zonas, así como las medias ponderales de todos los conceptos analíticos y relaciones correspondientes a cada par de zonas de cada probeta o muestra.

En todos los cuadros de conceptos analíticos y relaciones se hicieron constar medias aritméticas, medias ponderales y medias mixtas, correspondientes a todas las probetas o muestras de cada hormigón, por zonas $\left(A, A^{\prime} \mathrm{o} B\right)$. Las «medias mixtas» se denominan así por ser medias aritméticas de medias ponderales.

TABLA I

\begin{tabular}{|l|c|c|c|c|c|}
\hline \multicolumn{5}{|c|}{ Valores medios de los tres hormigones } \\
\hline $\begin{array}{l}\text { Zonas de los } \\
\text { hormigones }\end{array}$ & $\mathrm{A}$ & $\mathrm{A}$ & $\mathrm{A}$ & $\mathrm{d}$ & $\mathrm{e}$ \\
\hline $\mathrm{Cl}-$ & $\mathrm{B}$ & $\mathrm{AA}$ & $\mathrm{AB}$ \\
\hline $\mathrm{SO}_{3}$ & 0,098 & 0,087 & 0,074 & 0,092 & 0,083 \\
\hline $\mathrm{Na}_{2} \mathrm{O}$ & 0,665 & 0,596 & 0,395 & 0,732 & 0,442 \\
\hline $\mathrm{K}_{2} \mathrm{O}$ & 0,159 & 0,202 & 0,082 & 0,162 & 0,100 \\
\hline $\mathrm{Na}_{2} \mathrm{O}+\mathrm{K}_{2} \mathrm{O}$ & $0,21 \mathrm{I}$ & 0,258 & 0,085 & 0,207 & $0,1 \mathrm{I} 9$ \\
\hline $\mathrm{Cl}^{-} \mathrm{Na}_{2} \mathrm{O}+\mathrm{K}_{2} \mathrm{O}$ & 0,367 & 0,460 & 0,164 & 0,368 & 0,219 \\
\hline $\mathrm{SO}_{3} / \mathrm{Na}_{4} \mathrm{O}+\mathrm{K}_{2} \mathrm{O}$ & 2,577 & 0,256 & 0,461 & $0,44 \mathrm{I}$ & 0,436 \\
\hline
\end{tabular}

TABLA II

\begin{tabular}{|l|l|l|l|l|l|l|}
\hline \multicolumn{1}{|c|}{ Valores medios de los tres hormigunes } \\
\hline $\mathrm{Cl}-$ & $\mathrm{f}$ & $\mathrm{h}$ & $\mathrm{i}$ & $\mathrm{j}$ \\
\hline $\mathrm{SO} \mathrm{J}_{3}$ & $0,10 \mathrm{I}$ & 0,090 & $0,07 \mathrm{r}$ & 0,092 & 0,083 \\
\hline $\mathrm{Na}_{2} \mathrm{O}$ & 0,669 & 0,606 & $0,39 \mathrm{r}$ & 0,732 & 0,442 \\
\hline $\mathrm{K}_{2} \mathrm{O}$ & 0,149 & 0,203 & 0,082 & 0,162 & 0,100 \\
\hline $\mathrm{Na}_{2} \mathrm{O}+\mathrm{K}_{2} \mathrm{O}$ & 0,200 & 0,264 & 0,085 & 0,207 & 0,119 \\
\hline $\mathrm{Cl}^{-} / \mathrm{Na}_{2} \mathrm{O}+\mathrm{K}_{2} \mathrm{O}$ & 0,354 & 0,467 & 0,163 & 0,368 & 0,219 \\
\hline $\mathrm{SO}_{3} / \mathrm{Na}_{2} \mathrm{O}+\mathrm{K}_{2} \mathrm{O}$ & 2,654 & 0,275 & 0,449 & $0,44 \mathrm{1}$ & 0,436 \\
\hline
\end{tabular}


La inclusión de las tres series de cuadros (21 en total, con 15 filas en promedio y 15 columnas cada uno) llenaría un espacio excesivo, por lo cual se sustituye por la de las tablas-resumen I y II, que contienen los valores medios de los distintos conceptos analíticos y relaciones, calculados a partir de los valores medios de los cuadros no incluidos, y correspondientes a los tres hormigones *

En la tabla I se señalan las columnas $a, b, c, d$ y $e$, que corresponden, respectivamente, a las medias aritméticas de las zonas $A, A^{\prime}$ y $B$, y a las medias mixtas $A A^{\prime}$ y $A B$ correspondientes a las zonas $A$ y $A^{\prime}$, y $A$ y $B$, en cada caso. En la tabla II se indican las columnas $f, g$, $h, i$ y $j$, de las cuales las $f, g$ y $h$ corresponden, respectivamente, a las medias ponderales de las zonas $A, A^{\prime}$ y $B$, y las $i$ y $j$ representan las medias mixtas $A A^{\prime}$ y $A B$, como en la tabla $\mathrm{I}$.

Por lo que respecta a los hormigones 4 y $\mathbf{5}$, en cada laja de ambos se determinó el peso y el contenido de sulfatos $\left(\mathrm{SO}_{3}\right)$. Los resultados de este último se dan en las tablas III y IV.

TABLA III -

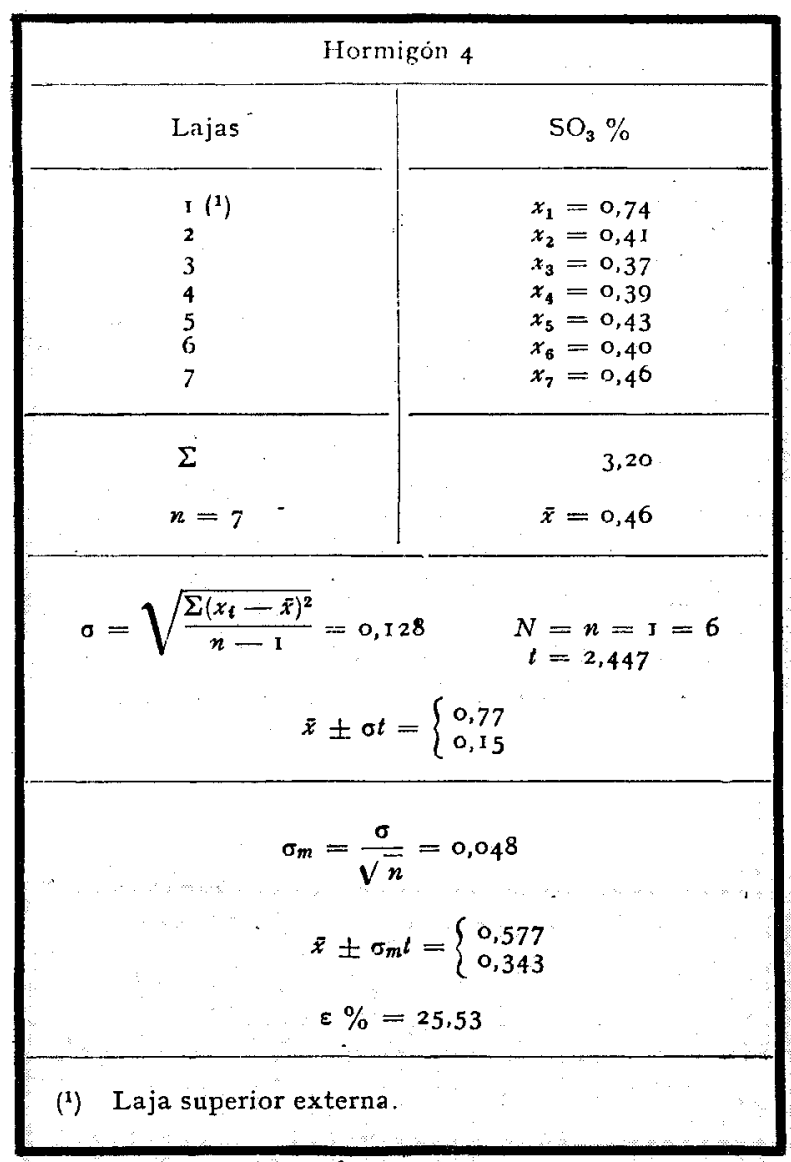

En el caso del hormigón 4 se determinó, además, en cada laja el contenido de azufre en el «mortero enriquecido», por fluorescencia de rayos $\mathrm{X}$; se expresó como $\mathrm{SO}_{3}$. Los resultados, en comparación con los obtenidos por análisis químico de vía húmeda, se dan en las tablas V a XI. El «mortero enriquecido» se separó por medios mecánicos y, como su

* Los cuadros omitidos figuran con todos sus detalles en la Monografía n..$^{\circ} 258$ del I. E. T. c. c. que lleva el mismo título que este trabajo. 
nombre indica, contiene prácticamente la totalidad de la pasta hidratada del conglomerante y una parte del árido fino-mortero-imposible o muy difícil de separar, pero carece de los áridos gruesos e intermedios (5).

2.3.2. DisCUSIÓN E INTERPRETACIÓN DE LOS RESULTADOS.-La interpretación de los resultados se hace a la vista de la tabla XII. En ella se han indicado, en la columna 1, los conceptos analíticos y relaciones, y en las restantes ( 2 a 6 ), y en las filas $a$ a $g$, las diversas zonas, por orden decreciente de izquierda a derecha de los respectivos valores analíticos y relaciones, extraídos de las tablas I y II.

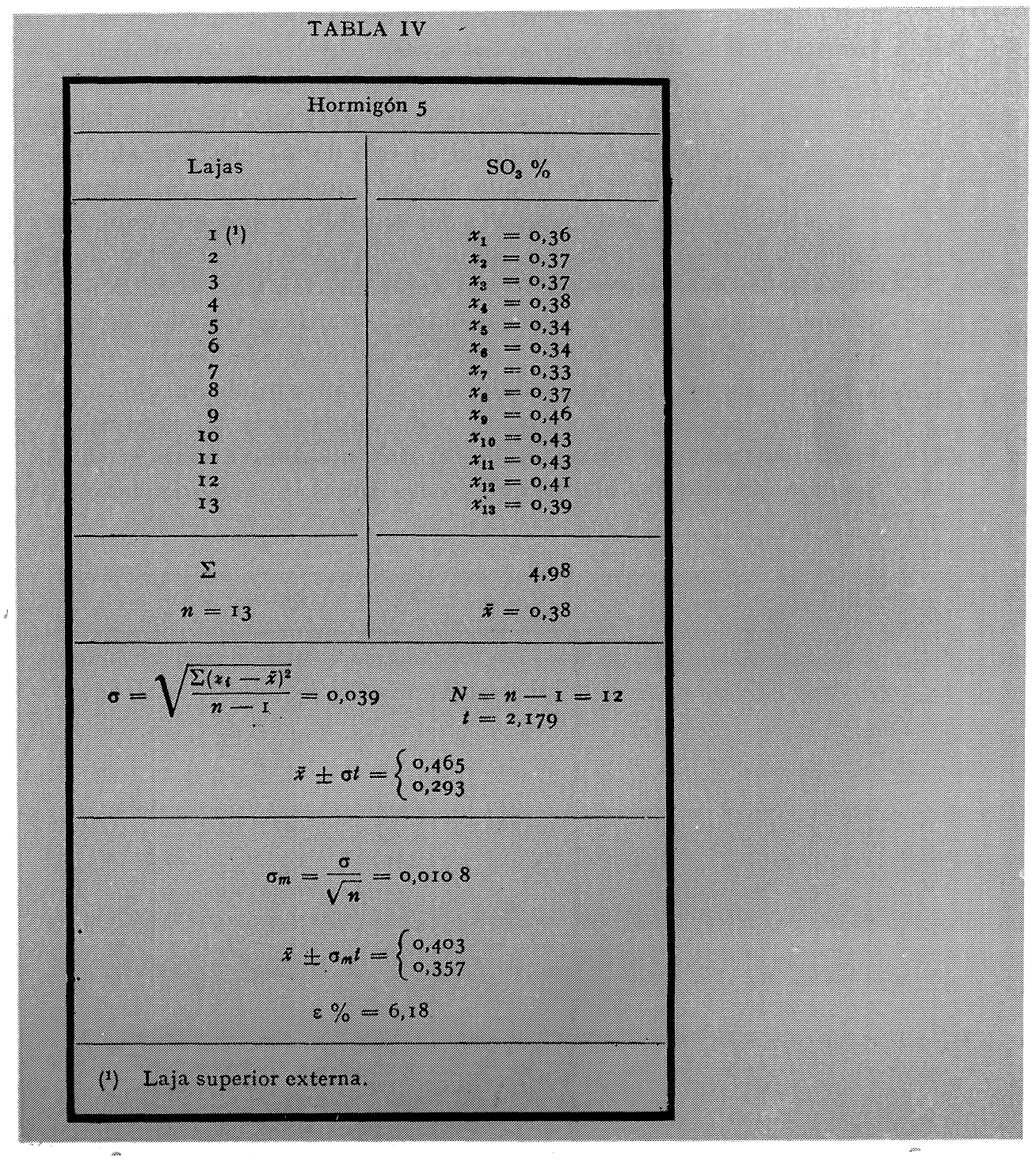

Si se consideran los conceptos analíticos (filas $a$ a $e$ ), se aprecia que todas las zonas $A$ y $A^{\prime}$ quedan situadas a la izquierda (columnas 2, 3 y 4), es decir, que les corresponden valores altos, y que todas las zonas $B$ quedan a la derecha (columna 6), es decir, que les correspon.den los valores más bajos. En la columna 5 entran todos los valores $A B$, esto es, los me- 
dios de las zonas $A$ y $B$ extremas (exterior e interior) de las probetas. Los valores $A A^{\prime}$, es decir, los medios de las zonas $A$ y $A^{\prime}$, contiguas y exteriores, encajan en las columnas 2,3 y 4 , y sobre todo en la 3 .

Todo ello quiere decir que los cloruros, sulfatos y álcalis solubles del hormigón, en virtud de un mecanismo de exudación probablemente, refluyen con la lechada de cemento hacia las partes superiores o externas, pudiendo ayudar también a ello un fenómeno de difusión, más lento, y que tendría lugar dentro de la fase líquida. De ser esto así, el orden de las zonas, de izquierda a derecha en la tabla XII, sería en todos los casos el siguiente: $A-A A^{\prime}-A^{\prime}$ $-A B-B$, como sucede con los cloruros (fila $a$ ). El hecho de que no ocurra en los demás casos (o en alguno de los tres hormigones en particular) puede explicarse tal vez por el mayor o menor lavado experimentado por las probetas, particularmente en sus partes superiores o externas (zonas A) durante su extracción con la sonda, tal como se hizo notar en el punto 2.1. Según eso, experimentarían más lavado las sales formadas a base de los álcalis $\mathrm{y}$ el anión sulfaţo (filas $b, c, d$ y $e$ de la tabla XII) que las formadas a base del ion cloro, a pesar de que es mayor la solubilidad en frío de los cloruros alcalinos que la de los sulfatos alcalinos; ello querría decir que el cloro queda retenido y fijado químicamente en forma poco soluble en la pasta fraguada del cemento, y que, encontrándose en tal estado, no forma cloruros alcalinos solubles y eliminables por lavado. Existen de hecho los cloroaluminatos cálcicos hidratados complejos que cumplen con tales condiciones. Existen también los sulfoaluminatos cálcicos hidratados complejos, análogos a ellos desde el punto de vista considerado, lo cual quiere decir que también podría quedar retenido y fijado el anión sulfato por el mismo mecanismo. Así sucede en parte, puesto que, precisamente en las zonas superiores y externas de las pastas de cemento de consistencia tal que experimentan exudación, se ha podido detectar por difracción de rayos $\mathrm{X}$ un contenido de ettringita (sulfoaluminato cálcico trisulfato hidratado) mayor que en las zonas internas de dichas pastas (1). Pero, por otra

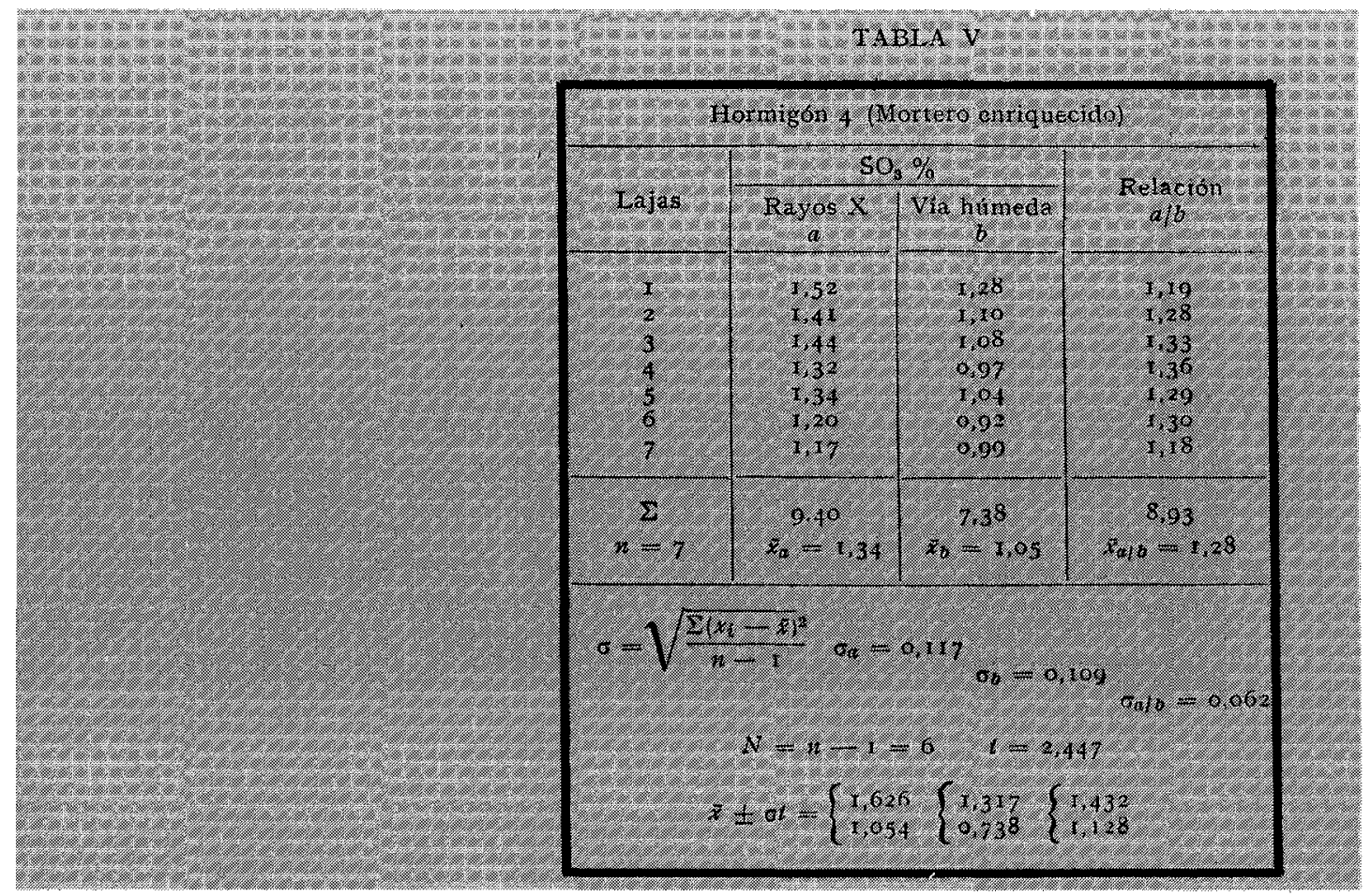


parte, también es cierto que en algunas probetas de los hormigones 1, 2 y $\mathbf{3}$ estudiados, y de otros muchos análogos a ellos, confeccionados con áridos y con conglomerantes semejantes, se han observado eflorescencias en las que la difracción de rayos $\mathrm{X}$ ha permitido detectar sulfatos alcalinos, particularmente sódico (el más soluble: glauberita o mirabilita $\mathrm{SO}_{4} \mathrm{Na}_{2} \cdot 10$ $-\mathrm{H}_{2} \mathrm{O}$ y thenardita $\mathrm{SO}_{4} \mathrm{Na}_{2}$ ), así como un sulfato doble sodo-potásico (aphthitalita $3 \mathrm{SO}_{4} \mathrm{~K}_{2} \cdot \mathrm{SO}_{4^{-}}$ $-\mathrm{Na}_{2}$ ) (6). Lo que muy verosímilmente sucede es que los sulfatos (y concretamente el sulfato cálcico - yeso- del cemento) son, al menos en este caso particular, mucho más abundantes que los cloruros; éstos quedan fijados en forma de sales complejas en su totalidad, mientras que de aquéllos aún queda una parte libre para formar sulfatos alcalinos solubles y dar lugar a las eflorescencias eliminables por lavado. La probabilidad de que esto sea así es muy grande, si se tiene en cuenta que los hormigones estudiados contenían sulfatos en cantidad superior a lo normal, sin duda por contenerlos el conglomerante con el que fueron confeccionados.

En cuanto a las relaciones (filas $f$ y $g$ de la tabla XII), éstas no siguen el orden anteriormente considerado, sino que la relación $\mathrm{Cl}-/ \mathrm{Na}_{2} \mathrm{O}+\mathrm{K}_{2} \mathrm{O}$ casi puede decirse que sigue un orden opuesto. Las consideraciones anteriormente expuestas permiten igualmente explicarlo. El orden de la relación $\mathrm{SO}_{3} / \mathrm{Na}_{2} \mathrm{O}+\mathrm{K}_{2} \mathrm{O}$ es más complicado, lo cual es lógico si se conside-

T A B L A V I

Hormigón 4

(Mortero enriquecido)

Comparación de métodos (resultados medios de la tabla V).

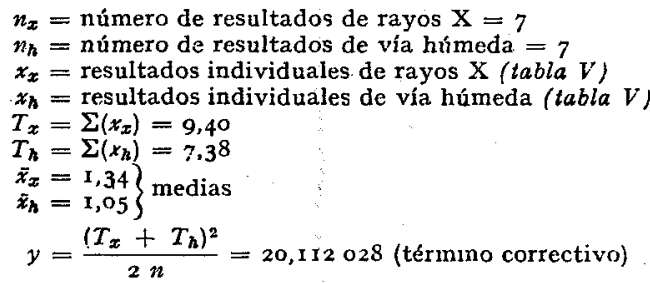

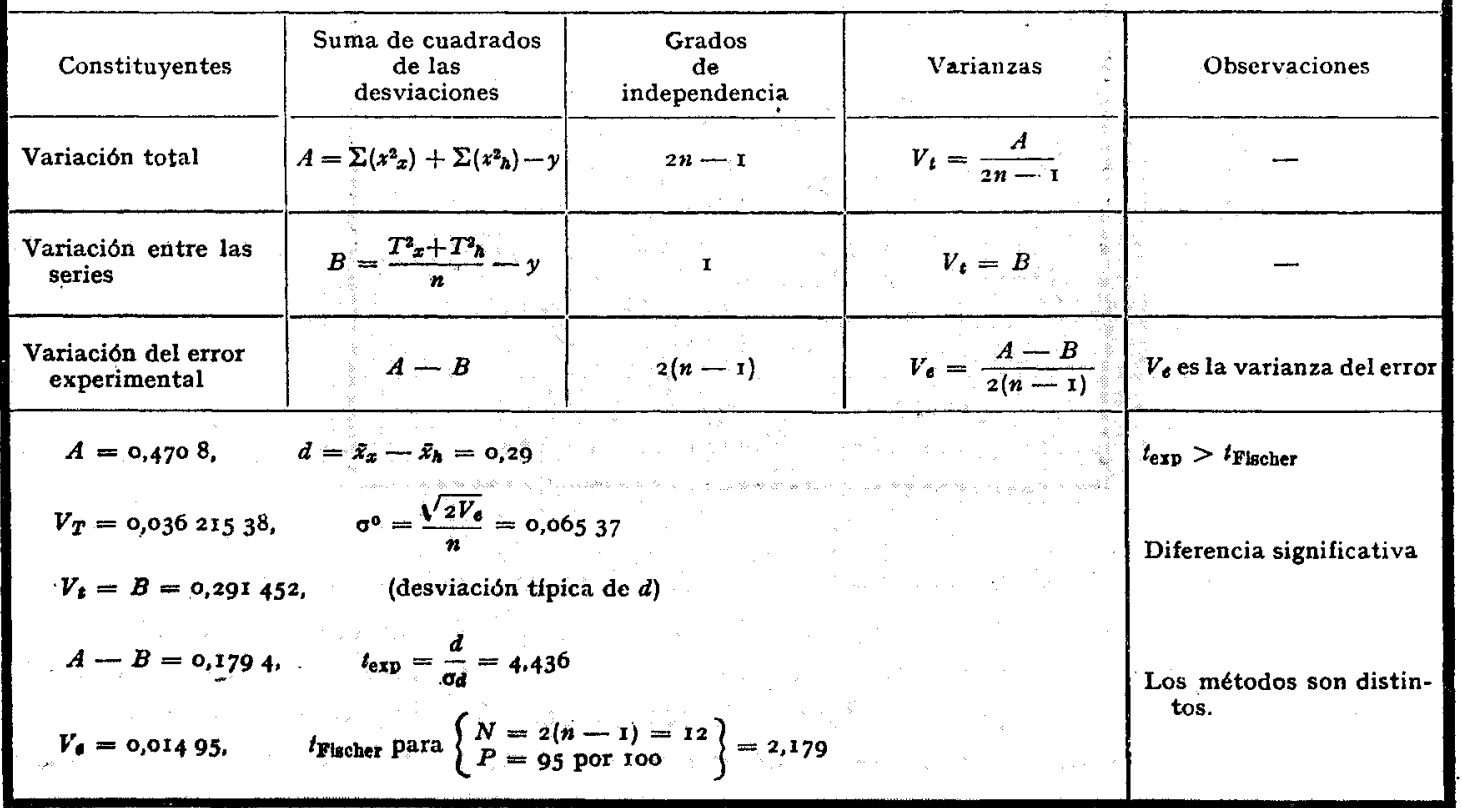


ran los sulfatos alcalinos sencillos y dobles que pueden formarse, así como su distinta solubilidad y capacidad de formar eflorescencias, $y$, por tanto, su más o menos fácil eliminación por lavado.

2.3.3. VALORACIÓN DE LOS RESUltados.-A partir de los resultados y datos calculados y expuestos en las tablas III a XI, puede hacerse una valoración estadística cuantitativa y más decisiva, orientada en el mismo sentido que lo señalado en el punto 2.3.2, y relativa a la heterogeneidad de distribución de los sulfatos en los hormigones defectuosos.

En efecto, en la tabla III se dan los contenidos de $\mathrm{SO}_{3}$ en tanto por ciento, determinados analíticamente por vía húmeda, de las siete lajas del hormigón 4. Se considera que en una distribución perfectamente homogénea los contenidos de las siete lajas deberían ser iguales $\mathrm{y}$, en consecuencia, los correspondientes siete valores se toman lícitamente como otras tantas determinaciones analíticas efectuadas en idénticas condiciones sobre una misma muestra

TABLA VII

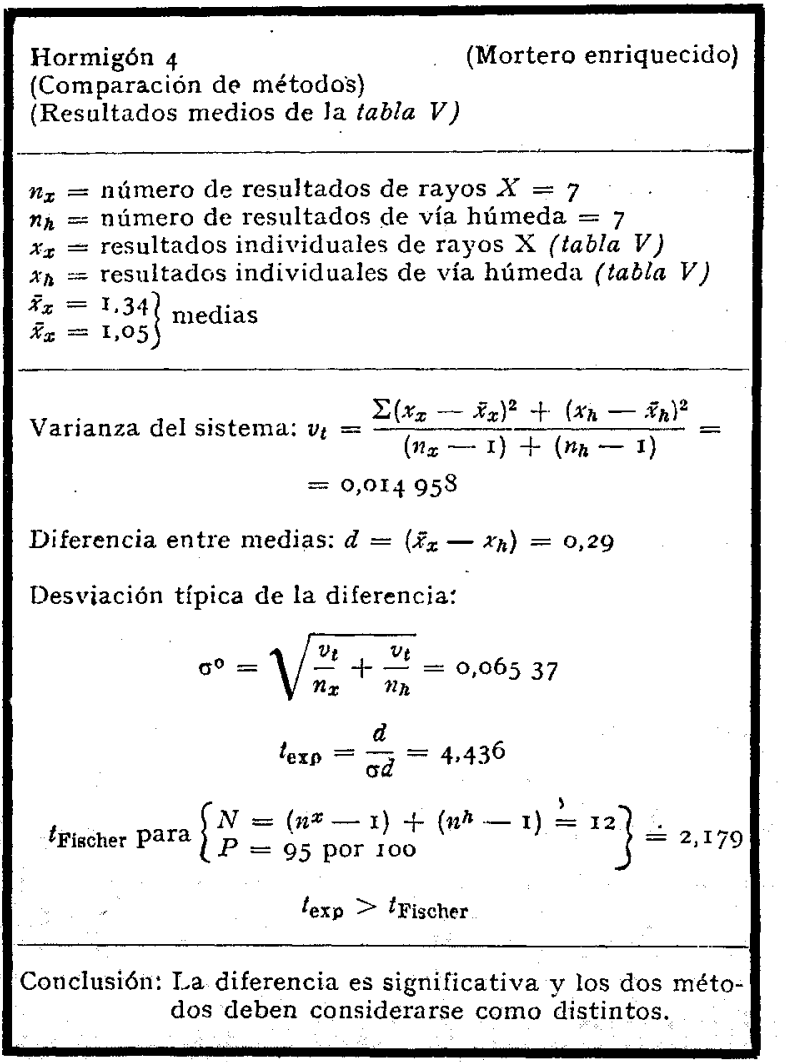

única del hormigón 4. Se ha calculado la media aritmética, así como la desviación típica y, a partir de ellas, y utilizando el correspondiente valor $t$ de Fischer (7), el intervalo $\bar{x} \pm \sigma t$, que comprende los valores aceptables como no aberrantes. Como puede apreciarse, no hay valores aberrantes en la serie de la tabla III, pese a que el primero, correspondiente a la laja 1 , se destaca notablemente de todos los demás, aproximándose bastante al límite superior del intervalo. 
Se ha recalculado la media de los valores 2 a 7 de la tabla III (descartando el valor 1), así como la desviación típica y el intervalo de confianza para una probabilidad del 95 por 100. Este intervalo está limitado por los valores 0,33 y 0,49 , saliéndose de él con mucho el valor 0,74 . Es decir, que si se dispusiera de la serie formada por los valores 2 a 7 y se considera el valor 1 como obtenido fuera de ella, la comparación de este valor con la serie llevaría a juzgarlo como defectuoso.

Se han calculado también la desviación media o error típico $\sigma_{\mathrm{m}}$ los límites $\bar{x} \pm \sigma_{\mathrm{n} 1} t$ del intervalo de confianza dentro de la cual la media tiene 95 por 100 de probabilidades de encontrarse, y el error relativo de dicha media para idéntica probabilidad.

La tabla IV presenta el mismo panorama respecto del hormigón-tipo, 5. Se puede advertir que la desviación típica es tres veces menor que para el hormigón 4. Tampoco hay valores aberrantes, y, si bien el correspondiente a la laja 9 está próximo al límite superior del intervalo, no llama, sin embargo, la atención por su desviación de la media, como sucede con el primer valor de la tabla III. La desviación media y el error relativo de la media son aproximadamente cuatro veces menores que los correspondientes del hormigón 4. También en este caso se ha recalculado la media de los valores 2 a 13 (descontando el valor 1 corres-

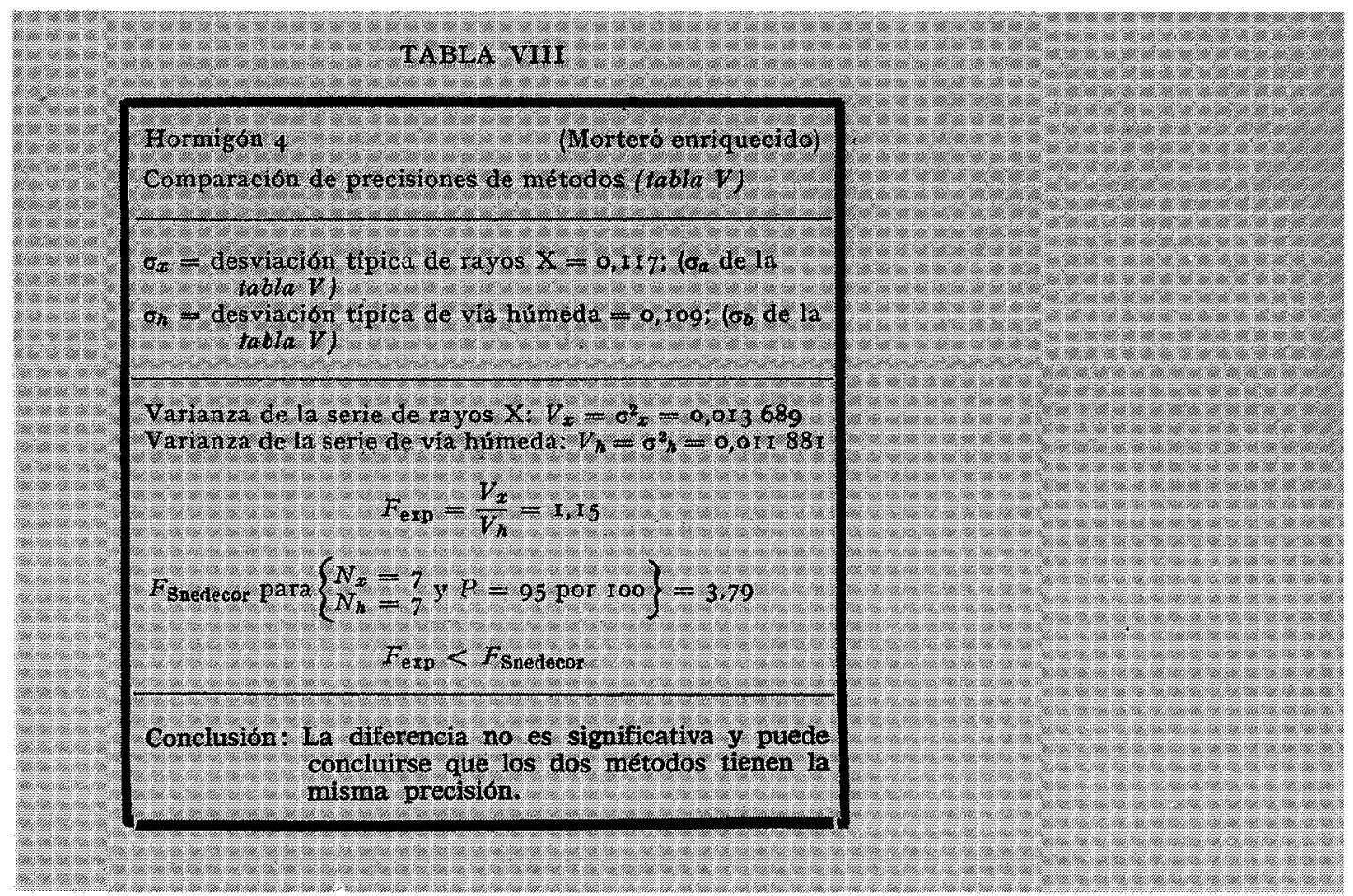

pondiente a la primera laja), así como la desviación típica y el intervalo de confianza para una probabilidad de 95 por 100. El intervalo está limitado por los valores 0,30 y 0,47 , quedando comprendido dentro del mismo el valor 0,36. Es decir, que si se dispusiera de la serie formada por los valores 2 a 13 y se considerara el valor 1 correspondiente a la primera laja como obtenido fuera de la misma, la comparación de este valor con la serie llevaría a aceptarlo como normal.

De otro modo, si se consideran los valores 0,74 y 0,36 correspondientes a las lajas número 1 de los hormigones 4 y 5 , respectivamente, como valores correctos del contenido de $\mathrm{SO}_{3}$ de los mismos, con la aplicación del criterio para la evaluación de errores sistemáticos. 
haciendo intervenir a las medias de los restantes valores, a las desviaciones típicas correspondientes $\mathrm{y}$ a las diferencias entre 0,74 y 0,36 , y las respectivas medias en cada caso, se tiene:

Hormigón 4:

$$
\begin{aligned}
& d=0,74-0,41=0,33, \\
& \sigma=0,0316, \\
& t_{\text {exp }}=\frac{d}{\sigma}=10,44 \\
& t_{\text {Fischer }} \text { para }\left\{\begin{array}{l}
N=n-1=5 \\
P=95 \text { por } 100
\end{array}\right\}=2,571 .
\end{aligned}
$$

Puesto que $t_{\text {exip }}>t_{\text {Fischer }}$, la serie mantenida de los seis resultados 2 a 7 daría un resultado distinto, prueba de un error sistemático del orden de la diferencia $d=0,33$.

\section{Hormigón 5:}

$$
\begin{aligned}
& d=0,36-0,385=-0,025, \\
& \sigma=0,0405, \\
& t_{\text {exp }}=\frac{0,025}{0,0405}=0,617, \\
& t_{\text {Fischer }} \text { para }\left\{\begin{array}{l}
N=n-1=11 \\
P=95 \text { por } 100
\end{array}\right\}=2,201 .
\end{aligned}
$$

Puesto que $t_{\text {exp }}<t_{\text {Fischer }}$, la serie mantenida de doce resultados 2 a 13 sería correcta.

Se calcula:

$$
\begin{gathered}
\sigma_{m}=\frac{\sigma}{\sqrt{n}}=\frac{0,0405}{12}=0,0117, \\
t_{\text {exp }}=\frac{0,025}{0,0117}=2,137 .
\end{gathered}
$$

Puesto que $t_{\text {exp }}<t_{\text {Fischer }}$, puede considerarse que la serie mantenida de los doce resultados 2 a 13 conduce al mismo resultado que el correspondiente a la laja 1, sin que exista error sistemático.

En consecuencia, el hormigón $\mathbf{5}$, «bueno», es más homogéneo que el hormigón 4, "deficiente». Es bien patente que la heterogeneidad de éste consiste en una acumulación de sulfatos en su parte externa o superficial.

Con análogas consideraciones a las hechas anteriormente, la tabla $\mathrm{V}$ presenta un estado comparativo de los valores analíticos hallados para el $\mathrm{SO}_{3}$ en el «mortero enriquecido» del hormigón 4, por vía húmeda y por fluorescencia de rayos $\mathrm{X}$. Los valores de rayos $\mathrm{X}$ son sis- 
temáticamente superiores a los químicos, pero las relaciones entre cada par de valores son muy próximas y distan poco de la media, como indica el bajo valor de la desviación típica correspondiente. Por otra parte, las desviaciones típicas de ambos métodos analíticos son prácticamente iguales, lo que indica que la dispersión es comparable y del mismo orden en los dos.

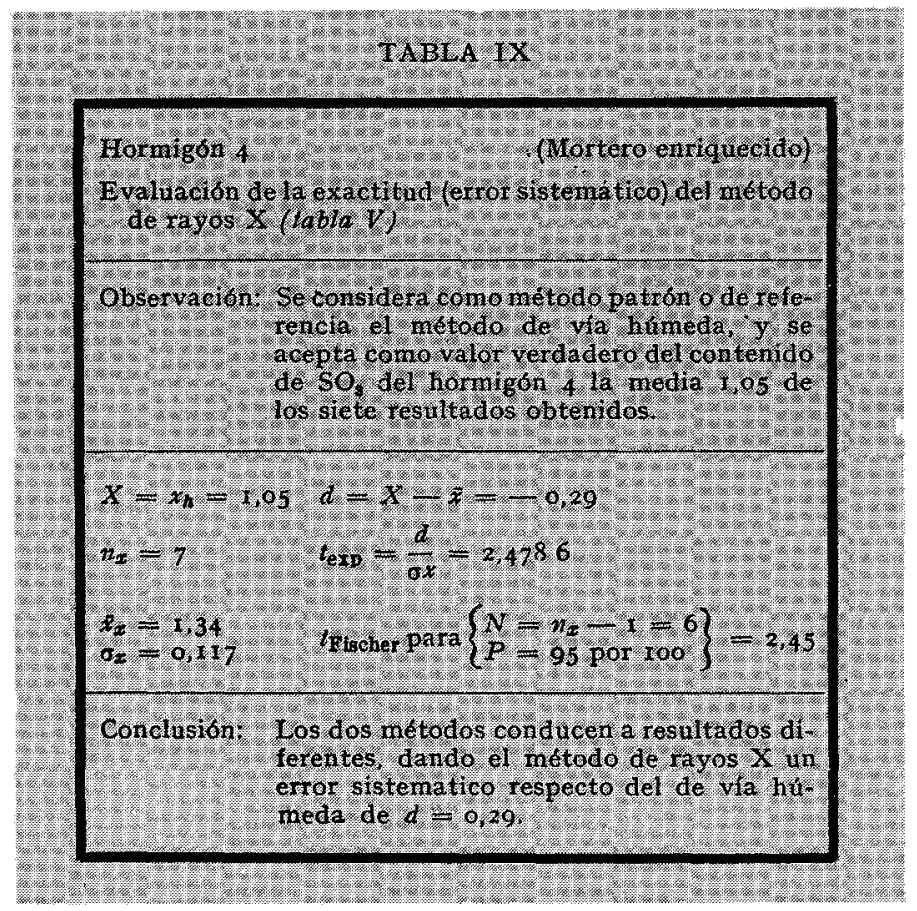

Un estudio estadístico más detallado aplicando el método de Fischer (7) permite comparar desde distintos puntos de vista y más a fondo ambos métodos, en principio diferentes.

a) Comparación de resultados medios.-Equivale a la comparación de los dos métodos en conjunto. El resultado de esta comparación, cuyos detalles se dan en las tablas VI y VII, es que las diferencias entre ambos métodos son significativas y que, por tanto, deben considerarse como distintos.

b) Comparación de precisiones.-Los resultados de la tabla VIII ponen de relieve que en cuanto a precisión, esto es, fidelidad o reproducibilidad, la diferencia entre ambos métodos no es significativa, lo que quiere decir que pueden considerarse como igualmente precisos.

c) Evaluación de la exactitud del método de rayos $X$ : determinación del error sistemático.-Anteriormente se indicó que el método de rayos $\mathrm{X}$ daba en apariencia resultados sistemáticamente superiores a los del método químico. Como confirmación de ello, si se admite como valor verdadero del contenido de $\mathrm{SO}_{3}$ del hormigón, la media de los resultados obtenidos por vía química $(1,05)$, los cálculos de la tabla IX ponen de relieve que el método de rayos $\mathrm{X}$ adolece de un error sistemático evaluable en $-0,29$.

d) Correlación.-Los cálculos de la tabla $\mathrm{X}$ relativos al coeficiente de correlación, a su error típico y al criterio de probabilidad, indican que dicho criterio es inferior a 0,05 (probabilidad de 95 por 100), es decir, que la correlación es significativa. 
e) Regresión.-La tabla XI indica que los resultados de los dos métodos no pueden relacionarse con suficiente rigor por una ecuación de tipo lineal tal que $y=0,81 x-0,03$, en la que $y$ representa resultados obtenidos por el método de rayos $\mathrm{X}$ y $x$ resultados obtenidos por vía química. La regresión no es significativa, a pesar de existir, como queda indicado en d), una cierta correlación.

TABLA $\mathrm{x}$

\begin{tabular}{|c|}
\hline $\begin{array}{l}\text { Hormigón } 4 \\
\text { Estudio de la correlación lineal entre los métodos de } \\
\text { rayos } \mathrm{X} \text { y de vía húmeda (tabla } V \text { ) }\end{array}$ \\
\hline 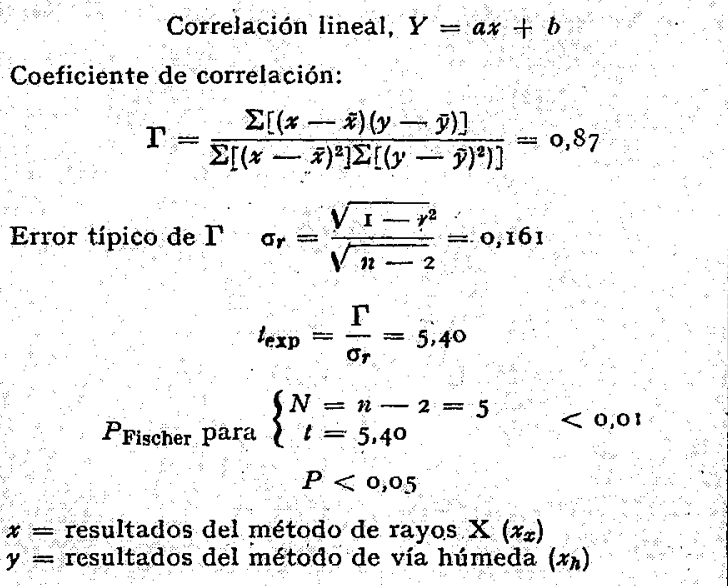 \\
\hline $\begin{array}{l}\text { Conclusión La correlación es significativa. Hay corre- } \\
\text { lación. }\end{array}$ \\
\hline
\end{tabular}

Los resultados del método de rayos $\mathrm{X}$ abonan, pues, en cierta medida, la validez de los hallados por vía química, en sustitución de un mayor número de determinaciones de este tipo, siempre más lentas y costosas. Los resultados de las determinaciones de $\mathrm{SO}_{3}$ por vía química, sobre los que se basa la discusión e interpretación, pueden considerarse como lícitamente válidos.

\section{CONCLUSIONES}

3.1.-El presente trabajo, tanto por las consideraciones previas como por los resultados experimentales, pone de relieve la existencia de heterogeneidades locales en la composición química de los hormigones, según la zona que de ellos se considere.

3.2.-Las heterogeneidades se dan de forma más acusada en hormigones defectuosos por sus materiales, por su dosificación, por su granulometría, por su relación agua/cemento, o por su confección y puesta en obra; en suma, defectuosos por su proyecto y/o por su ejecución.

3.3.- Las heterogeneidades se presentan preferentemente en las partes externas, laterales y superiores de las piezas o elementos estructurales del hormigón, en relación con la masa del mismo. 


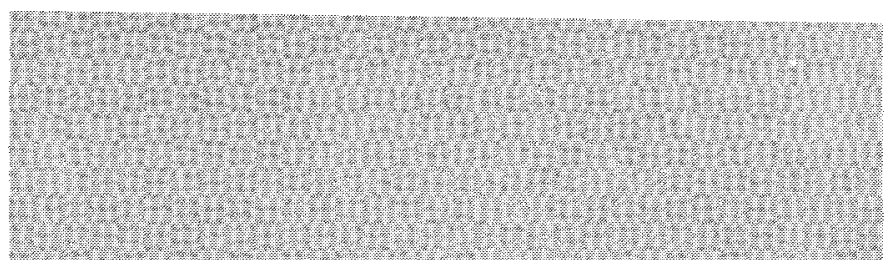

3.4.-Las heterogeneídades, que tienen como causa 10 señalado en 3.2 , se pueden producir por un mecanismo complejo en el que pueden intervenir fenómenos de segregación, sedimentación, exudación, reflujo y pérdida de lechada de cemento, dífusión, "efecto pared" de encofrados y moldes, vibración, evaporación y carbonatación superficiales, formación y emigración de eflorescencias, etc.

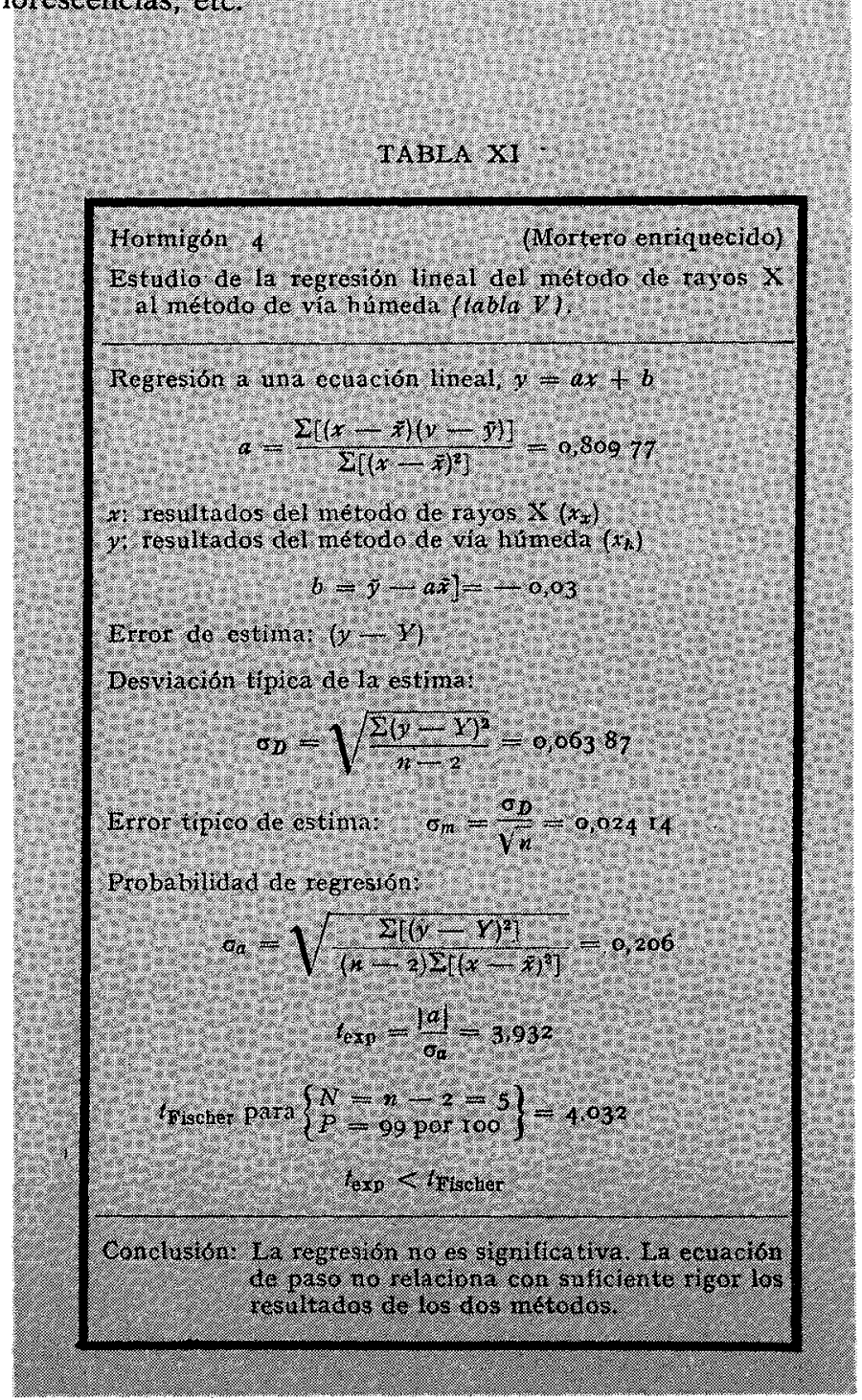

3.5.-Las heterogeneidades de composición química de los hormigones se manifiestan en los casos y condiciones señalados, por un enriquecimiento superficial y de las zonas exteriores en pasta y lechada de cemento, en partículas finas del conglomerante -incluidas las del retardador de naturaleza sulfatada- y por un mayor contenido de cloruros y álcalis -principalmente- en dichas zonas.

3.6.-Cuando esto ocurre de manera muy ostensible, a efectos determinados, el hormigón de las zonas más externas puede - y hasta debe - considerarse como distinto al del resto de la masa; por ejemplo, en cuanto a permeabilidad, durabilidad, resistencia al hielo, resistencia a la abrasión, efectos de las eflorescencias, etc. 


\section{CONSECUENCIAS}

Las conclusiones anteriores, y siempre en los casos más acusados de heterogeneidad, que, como se ha indicado, se dan precisamente en hormigones de baja calidad, aconsejan tener en cuenta lo expuesto. Es frecuente intentar juzgar hormigones -en la mayoría de los casos ya sospechosos- a base de "pruebas químicas", asentando el juicio definitivo sobre los resultados analíticos. Pero sucede que, si los hormigones ya fraguados forman parte de estructuras, no es posible destruir éstas en su totalidad, ni siquiera alguno o algunos elementos de ellas, para obtener una muestra representativa del material; es el problema permanente de la «toma de muestras» en uno de los casos más difíciles de resolver a satisfacción. En una situación semejante no cabe otra alternativa que sacar testigos del hormigón de los elementos estructurales que se quiera estudiar. Estos testigos deberán tener las dimensiones adecuadas. El ideal, como bien indican los datos de la tabla IV, relativos a un testigo de longitud igual al espesor de la viga de la que fue extraído, es precisamente éste: que su longitud o altura sea igual al espesor de la pieza o elemento estructural de que procede. Si esto no es posible, cuando menos debe procurarse que dicha longitud o altura no sea inferior a

TABLA XII

\begin{tabular}{|c|c|c|c|c|c|c|}
\hline & \multicolumn{6}{|c|}{ Ordenación de valores de mayor a menor $\rightarrow$} \\
\hline & I & 2 & 3 & 4 & 5 & 6 \\
\hline$a$ & $\mathrm{Cl}^{-}$ & $A$ & $A A^{\prime}:$ & $A^{\prime}$ & $A B$ & $B$ \\
\hline$b$ & $\mathrm{SO}_{3}$ & $A A$ & $A$. & $A^{\prime} \cdot 1$ & $A B$ & $B$ \\
\hline$c$ & $\mathrm{Na}_{2} \mathrm{O}$ & $A^{\prime}$ & $A A^{\prime}$ & $A$ & $A B$ & $B$ \\
\hline$d$ & $\mathrm{~K}_{2} \mathrm{O}$ & $A^{\prime}$ & $A\left(A A^{\prime}\right)$ & $A A^{\prime}(A)$ & $A B$ & $B$ \\
\hline$e$ & $\mathrm{Na}_{2} \mathrm{O}+\mathrm{K}_{2} \mathrm{O}$ & $A^{\prime}$ & $A A^{\circ}$ & $A$ & $A B$ & $B$ \\
\hline$t$ & $\frac{\mathrm{Cl}}{\mathrm{Na}_{2} \mathrm{O}+\mathrm{K}_{2} \mathrm{O}}$ & $B$ & $A A^{\prime}$ & $A B$ & $A$ & $A^{\prime}$ \\
\hline 8 & $\frac{\mathrm{SO}_{3}}{\mathrm{Na}_{2} \mathrm{O}+\mathrm{K}_{2} \mathrm{O}}$ & $A A^{\prime}$ & $A$ & $B$ & $A B$ & $A^{\prime}$ \\
\hline $\begin{array}{l}A \\
B \\
A^{\prime} \\
A A^{\prime} \\
A B\end{array}$ & $\begin{array}{l}\text { : Zona superi } \\
\text { : Zona intern } \\
\text { : Zona intern } \\
\text { : Promedios }\end{array}$ & $\begin{array}{l}\text { ior o e } \\
\text { na. } \\
\text { media. } \\
\text { de zon }\end{array}$ & $\begin{array}{l}\text { Xterna. } \\
\text { as. }\end{array}$ & & & \\
\hline
\end{tabular}

la mitad del grosor del elemento; así, pese a algunas posibles "disimetrías" de composición como la que muestran las dos mitades - superior de 1 a 6 ó 7, e inferior de 6 ó 7 a 13de los datos de la propia tabla IV, y que indudablemente pueden introducir algún error, éste es tolerable, en general. No es admisible, en cambio, basar un dictamen sobre cualquier aspecto de un hormigón, en datos analíticos químicos obtenidos de unos trozos o esquir- 
las superficiales del material arrancadas de una cara vista, o de una esquina o arista del elemento estructural que se trate de estudiar. Los errores, en tal caso, pueden llegar a ser del orden del 60 por 100, como pone de relieve el contenido de $\mathrm{SO}_{3}$ de la laja 1 del hormigón 4 (tabla III), y aún mayores, respecto del valor medio - valor real-correspondiente a dicho hormigón.

Todo juicio fundado en datos químicos, y que puede versar sobre problemas del hormigón tan vitales como la estabilidad de volumen o la durabilidad de las estructuras a largo plazo, deberá tener en cuenta estas consideraciones, bajo riesgo de ser erróneo, e incluso opuesto a la realidad de los hechoś.

2.7.

\section{blbliografia}

(1) Calleja, J., y Triviño, F.; «El agrietamiento superficial de las pastas de cemento: una interpretación»; Materiales de Construcción - Ultimos avances (I.E.T.C.C.), núm. 116, 1964.

(2) Fernández París, J. M.; «Determinación rápida del ion cloruro en yesos, arcillas y cementos»; Materiales de Construcción - Ultimos avances (I.E.T.C.C.), núm. 90, 1958.

(3) Triviño, F.; «Fotometría de llama aplicada a la determinación de álcalis en cementos. Puesta a punto del equipo y de los métodos»; Monografía núm. 246 (I.E.T.C.C.), Madrid, 1965.

(4) Triviño, F., y Sagrera, J. L.; «Técnica general de análisis por espectrografía de rayos $\mathrm{X}$ con equipo Philips tipo PW 1540»; Monografía nüm. 251 (I.E.T.C.C.), Madrid, 1965.

(5) Calleja, J.; "Observaciones acerca de la dosificación de cemento en morteros y hormigones fraguados"; Informes de la Construcción (I.E.T.C.C.), núm. 173, 1965.

(6) Calleja, J., y Triviño, F.; Trabajo en curso, 1965.

(7) Lacroix, Y.; Analyse Chimique; interprétation des résuttats par le calcul statistique. Ed. Masson et Cie., París, 1962. 